\title{
Manejo de água no comportamento da cultura principal e da soca de arroz irrigado(1)
}

\author{
Alberto Baêta dos Santos ${ }^{(2)}$, Evane Ferreira ${ }^{(2)}$, Luís Fernando Stone ${ }^{(2)}$, \\ Silvando Carlos da Silva ${ }^{(2)}$ e Cristina Guimarães Ramos ${ }^{(3)}$
}

\begin{abstract}
Resumo - O cultivo da soca de arroz (Oryza sativa L.) pode se constituir em uma fonte de renda importante se o manejo da água de irrigação for adequado. O objetivo deste estudo foi determinar os efeitos de períodos de drenagem e de irrigação, antes e depois, respectivamente, da colheita da cultura principal sobre o comportamento da cultura principal e da soca de arroz. Os tratamentos consistiram da combinação de quatro períodos de drenagem (corte da irrigação e abertura dos drenos aos $0,10,20$ e 30 dias) antes da colheita da cultura principal, com o reinício da irrigação aos $0,10,20$ e 30 dias após a colheita da cultura principal, em arranjo fatorial $4 \times 4$, no delineamento experimental de blocos ao acaso, com quatro repetições. Os períodos de irrigação após a colheita afetaram diferentemente o comportamento da soca de arroz de acordo com as condições climáticas. Com temperaturas do ar mais baixas, o atraso no reinício da irrigação reduziu a produtividade e a qualidade do produto colhido. Em condições climáticas de temperaturas do ar mais altas, a inundação iniciada nove dias após a colheita da cultura principal resultou em melhor desempenho da soca, com uma economia de água de $14 \%$ em relação à inundação imediatamente após a colheita. A soca aparentemente não se apresenta favorável ao desenvolvimento de populações daninhas de larvas da bicheira-da-raiz do arroz, Oryzophagus oryzae.
\end{abstract}

Termos para indexação: Oryza sativa, irrigação, drenagem, fator climático, rendimento de cultura, qualidade do grão.

\section{Water management on the performance of flooded rice main and ratoon crop}

\begin{abstract}
The cultivation of flooded rice (Oryza sativa L.) ratoon crop may constitute a profitable activity, if an adequate water management is adapted. The objective of this study was to determine the effects of drainage and irrigation periods, before and after, respectively, main crop harvest on the performance of flooded rice main and ratoon crop. Treatments consisted of the combination of four drainage periods $(0,10,20$, and 30 days) before the main crop harvest with the introduction of irrigation at $0,10,20$, and 30 days after the main crop harvest. The experimental design was a randomized complete block in a $4 \times 4$ factorial scheme, with four replication. The rice ratoon crop performance was differently affected by the irrigation periods after main crop harvest according to environmental conditions. Retardation in flooding decreased grain yield and grain quality, when air temperatures unsuitable to ratoon crop development occurred. Under suitable air temperatures conditions, starting flooding at nine days after the main crop harvest was the best treatment to the performance of ratoon crop, which represented $14 \%$ of saved irrigation water. Rice ratoon crop apparently is not favorable to the development of Oryzophagus oryzae harmful population.
\end{abstract}

Index terms: Oryza sativa, irrigation, drainage, climatic factors, crop yield, grain quality.

\footnotetext{
(1) Aceito para publicação em 30 de abril de 2002.

(2) Embrapa-Centro Nacional de Pesquisa de Arroz e Feijão, Caixa Postal 179, CEP 75375-000 Santo Antônio de Goiás, GO. Bolsista do CNPq. E-mail: baeta@cnpaf.embrapa.br, evane@cnpaf.embrapa.br, stone@cnpaf.embrapa.br, silvando@cnpaf.embrapa.br

(3) Universidade Federal de Goiás, Caixa Postal 131, CEP 74001-970 Goiânia, GO. Bolsista do CNPq. E-mail: cramos@agricultura.go.br
}

\section{Introdução}

A soca, que é a capacidade das plantas de arroz (Oryza sativa L.) de regenerar novos perfilhos férteis após o corte dos colmos para a colheita, pode se constituir numa prática para aumentar a produção de arroz por unidade de área e de tempo.

O suprimento adequado de água é um fator indispensável no aumento do nível de produtividade do 
cultivo principal e da soca. A soca requer cerca de $60 \%$ da quantidade de água normalmente exigida pela cultura principal, e a época de inundação afeta o seu comportamento. Pesquisas realizadas em diversas regiões do mundo indicam que a produtividade da soca é influenciada pelo manejo da água e pelas técnicas de colheita da cultura principal (Chauhan et al., 1985).

A drenagem do tabuleiro antes da colheita da cultura principal é uma prática recomendada para maior produção de perfilhos e uniformidade no florescimento e na maturação da soca (Chauhan et al., 1985). O manejo da água pode afetar também o desenvolvimento radicular do arroz. As plantas de arroz irrigado são adaptadas ao crescimento em ambiente anaeróbico provocado pela inundação contínua. Além da alta capacidade de perfilhamento, um vigoroso sistema radicular é uma importante característica que as cultivares devem apresentar para a obtenção de altas produtividades de grãos na soca. A disponibilidade de água no solo favorece a taxa fotossintética nas folhas, o acúmulo de massa e a produção de carboidratos. Entretanto, este efeito pode ocorrer em solo apenas saturado, e não depende da presença da lâmina de água sobre a superfície.

O baixo requerimento de água e a maior eficiência de seu uso são relatados como as principais vantagens do cultivo da soca (Prashar, 1970a, 1970b). Santos (1999) menciona que o menor consumo de água apresenta maior importância nas regiões onde a água de irrigação é bombeada, e tem grande participação no custo de produção do arroz. Esse mesmo autor verificou que o uso de banhos periódicos durante o desenvolvimento da soca proporcionou uma redução no consumo de água de $1 \mathrm{~L} \mathrm{~s}^{-1} \mathrm{ha}^{-1}$, em comparação ao emprego de lâmina contínua, sem afetar a produtividade da soca.

O manejo da água antes e após a colheita da cultura principal afeta a capacidade produtiva da soca (Prashar, 1970a, 1970b; Votong, 1975; Bahar \& De Datta, 1977; Nadal \& Carangal, 1979). A disponibilidade de água, isoladamente, não garante êxito na produção da soca; é necessário, também, que haja água disponível para o cultivo na época adequada. A resposta da soca de arroz irrigado à época de retorno da inundação está relacionada à altura de corte das plantas. Prashar (1970a, 1970b) obteve interação significativa entre a altura do corte e a época da primeira irrigação sobre a porcentagem de perfilhamento; na menor altura do corte, o atraso na irrigação de quatro para seis dias propiciou porcentuais superiores aos da irrigação efetuada um dia após o corte. $\mathrm{O}$ aumento do período da colheita ao reinício da irrigação teve efeito pouco consistente na produtividade da soca (Votong, 1975), porém o crescimento de plantas daninhas foi substancialmente reduzido. A irrigação tardia pode resultar em severa competição entre as plantas daninhas e a soca. Bahar \& De Datta (1977) relataram que, quando a cultura principal foi cortada no nível do solo, o atraso na irrigação da soca em até 12 dias após a colheita da cultura principal aumentou a sua produtividade; entretanto, quando o corte foi feito a $15 \mathrm{~cm}$ de altura, a produtividade não foi afetada. Mengel \& Wilson (1981) constataram que a inundação contínua com uma lâmina de água de $5 \mathrm{~cm}$ a $8 \mathrm{~cm}$, aplicada imediatamente após a colheita da cultura principal, propiciou aumento de $68 \%$ na produtividade da soca em comparação com irrigações intermitentes (banhos), até que os perfilhos da soca atingissem $10 \mathrm{~cm}$ a $15 \mathrm{~cm}$ de altura, seguidas de inundação contínua. Segundo esses autores, a antecipação da inundação criou condições mais favoráveis para uma brotação mais rápida e uniforme, resultando em plantas com maior capacidade de utilização de nitrogênio. $\mathrm{Na}$ colheita, as plantas foram cortadas de $40 \mathrm{~cm}$ a $45 \mathrm{~cm}$ de altura, e portanto, não houve risco de apodrecimento dos colmos pela submersão. Resposta quadrática da produtividade da soca com o período de drenagem após a maturação da cultura principal foi obtida por Coale \& Jones (1994), e a produtividade máxima estimada foi com 28 dias de drenagem.

O objetivo deste trabalho foi determinar os efeitos de períodos de drenagem, antes e depois da colheita da cultura principal, no comportamento da cultura principal e da soca de arroz irrigado.

\section{Material e Métodos}

O experimento foi realizado por três anos consecutivos (1997/1998, 1998/1999 e 1999/2000), na Fazenda Palmital, da Embrapa-Centro Nacional de Pesquisa de Arroz e Feijão, no Município de Goianira, GO, em solo Gley Pouco Húmico, textura franco-argilo-arenosa. As análises químicas e granulométricas das amostras de 
solo coletadas no início do estudo, nas camadas de 0 a $20 \mathrm{~cm}$ e de 20 a $40 \mathrm{~cm}$ de profundidade, revelaram $\mathrm{pH}$ em água $(1: 2,5)$ de 5,4 e 5,6; 2,8 e 3,4 cmol $_{\mathrm{c}} \mathrm{kg}^{-1}$ de $\mathrm{Ca}^{2+} ; 1,9$ e $1,9 \mathrm{cmol}_{\mathrm{c}} \mathrm{kg}^{-1}$ de $\mathrm{Mg}^{2+}$; 6,5 e 5,3 $\mathrm{mg} \mathrm{kg}^{-1}$ de P; 27 e $31 \mathrm{mg} \mathrm{kg}^{-1} \mathrm{de} \mathrm{K}^{+}$; 4,0 e 3,5 mg kg-1 de Cu; 2,0 e 1,7 mg kg-1

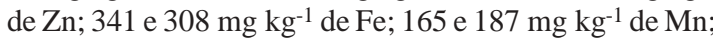
8 e $9 \mathrm{~g} \mathrm{~kg}^{-1}$ de matéria orgânica; $285 \mathrm{~g} \mathrm{~kg}^{-1}$ de argila; $120 \mathrm{~g} \mathrm{~kg}^{-1}$ de silte; $595 \mathrm{~g} \mathrm{~kg}^{-1}$ de areia, respectivamente.

O manejo de água consistiu da combinação de quatro períodos de drenagem (corte da irrigação e abertura dos drenos aos $0,10,20$ e 30 dias) antes da colheita da cultura principal com o reinício da irrigação aos $0,10,20$ e 30 dias após a colheita da cultura principal, em arranjo fatorial $4 \times 4$, constituindo, portanto, 16 tratamentos. O delineamento experimental foi o de blocos ao acaso, com quatro repetições. A irrigação da cultura principal e da soca foi por inundação com lâmina de água de $10-15 \mathrm{~cm}$.

Nos dois primeiros anos, foi usada a cultivar Formoso, e no último, a linhagem CNA 8502, no sistema de semeadura em linhas, com espaçamento de $20 \mathrm{~cm}$ com 80 sementes por metro. Por ocasião da adubação da cultura principal, aplicaram-se $400 \mathrm{~kg} \mathrm{ha}^{-1}$ do formulado 5-30-15 e $30 \mathrm{~kg} \mathrm{ha}^{-1}$ de $\mathrm{N}$ (sulfato de amônio) no perfilhamento, na diferenciação do primórdio floral e na época do emborrachamento, e na soca, $40 \mathrm{~kg} \mathrm{ha}^{-1}$ de $\mathrm{N}$, imediatamente após a colheita. $\mathrm{O}$ corte das plantas da cultura principal foi realizado a cerca de $25 \mathrm{~cm}$ acima do nível do solo. A competição com as plantas daninhas foi prevenida com a aplicação do herbicida oxadiazon na dose de $800 \mathrm{~g} \mathrm{ha}^{-1} \mathrm{de}$ ingrediente ativo em pré-emergência.

O índice de colheita foi obtido pela relação entre a produção de grãos e a de matéria seca total em $1 \mathrm{~m}^{2}$.

Foram efetuados levantamentos para avaliar a infestação de larvas de Oryzophagus oryzae, conhecidas como bicheira-da-raiz do arroz, no início e no término da aplicação dos tratamentos, retirando-se duas amostras em sentido diagonal da parcela. Cada amostra consistiu em cortar $10 \mathrm{~cm}$ de fileira de plantas, no nível do solo, onde um cilindro de ferro de $10 \mathrm{~cm}$ de diâmetro por $12 \mathrm{~cm}$ de altura foi totalmente enterrado para retirar o solo e as raízes, os quais foram lavados sobre uma peneira com malha de $1 \mathrm{~mm}$ para contagem das larvas. A severidade de mancha-parda, causada pelo fungo Drechslera oryzae (Breda de Haan), foi determinada pelo número de lesões por área da folhabandeira e nos grãos, por ocasião da colheita da cultura principal e da soca. Foram determinados, na colheita, o número de perfilhos e de panículas por $\mathrm{m}^{2}$, o número de grãos e de espiguetas vazias por panícula, a massa de 100 grãos, a altura de plantas e a produção de grãos, a qual foi expressa em $\mathrm{kg} \mathrm{ha}^{-1}$, após ajustada em $13 \%$ de umidade.

Na determinação do consumo de água foram levados em consideração a duração dos períodos de irrigação da soca, a saber: $64,54,44$ e 34 dias, contados a partir do reinício da irrigação aos $0,10,20$ e 30 dias, respectivamente, após a colheita da cultura principal; as perdas por percolação e fluxo lateral foram consideradas igual a $58,3 \mathrm{~mm} \mathrm{dia}^{-1}$, conforme Stone et al. (1990); a evapotranspiração da cultura foi estimada a partir da evapotranspiração de referência determinada por meio do tanque Classe A, considerando o valor do coeficiente de cultura igual a 1,05 (Doorenbos \& Pruitt, 1976).

A qualidade tecnológica dos grãos foi avaliada por meio de rendimento industrial, classificação visual (comprimento, largura e "centro branco"), temperatura de gelatinização e conteúdo de amilose.

Os dados foram submetidos à análise de variância e, quando significativos, à análise de regressão.

\section{Resultados e Discussão}

A soca apresentou comportamento diferenciado em cada ano que o estudo foi realizado, especialmente no último, em comparação aos dois primeiros anos, o que pode ser atribuído às variações climáticas observadas. Nos dois primeiros anos houve ocorrência de baixas temperaturas do ar (Figura 1), principalmente nos períodos de pré-floração e floração, afetando o crescimento e desenvolvimento da soca, resultando em menor produtividade. A temperatura foi relatada por Yoshida (1981) como o fator climático mais importante para a planta de arroz, com valores críticos, tanto baixos quanto altos, dependendo da fase da cultura, mas, no geral, valores inferiores a $20^{\circ} \mathrm{C}$ e superiores a $30^{\circ} \mathrm{C}$ são prejudiciais. As temperaturas críticas variam com a cultivar, o grau, e sua duração, o estádio de desenvolvimento da planta e com as práticas culturais.

Os períodos de drenagem antes da colheita da cultura principal não influenciaram qualquer característica da cultura principal e da soca, nem houve interação destes com os períodos de reinício da irrigação após a colheita.

Nos dois primeiros anos, houve redução do número de panículas por $\mathrm{m}^{2}$ e da altura de plantas da soca com o aumento dos períodos de reinício da irrigação após a colheita e, no último, aumento linear do número de panículas e resposta quadrática da altura de plantas (Tabela 1). O porte máximo estimado das plantas foi de $63 \mathrm{~cm}$, com reinício da irrigação aos 13 dias. A redução do porte na soca com os maiores períodos de drenagem após a colheita da cultura principal não foi suficiente para que se pudesse prever 
dificuldades com a colheita mecanizada. Entre os fatores ambientais que afetam o crescimento e desenvolvimento das plantas, a temperatura e a luz são os de maior influência no comportamento da soca, particularmente no perfilhamento (De Datta \& Bernasor, 1988). A redução do número de perfilhos férteis da soca com a antecipação do reinício da inundação após a colheita somente foi verificada por Bahar \& De Datta (1977), quando as plantas da cultura principal foram cortadas ao nível do solo. Contudo, quando o corte foi feito a $15 \mathrm{~cm}$ de altura, o tempo de reinício da irrigação não afetou o número de perfilhos, nem a produtividade da soca.

Votong (1975) também verificou incremento do número de panículas por $\mathrm{m}^{2} \mathrm{e}$ decréscimo da porcentagem de perfilhos férteis e de esterilidade de espiguetas com o aumento do período de drenagem. Avaliando as características agronômicas que se correlacionam com o comportamento de ambas as colheitas, Costa et al. (2000a) concluíram que o número de panículas por $\mathrm{m}^{2}$ e o de perfilhos por $\mathrm{m}^{2}$ apresentaram os mais altos coeficientes de correlação com a produtividade da soca.

A porcentagem de fertilidade de espiguetas declinou linearmente com o aumento dos períodos de reinício da irrigação após a colheita, no primeiro ano, e apresentou resposta quadrática, no último, sendo o valor máximo estimado de $93 \%$ com nove dias de drenagem (Tabela 1). Jennings et al. (1979) consideram que, para a obtenção de altas produtividades, a esterilidade normal de espiguetas deve ser de $10 \%$ a 15\%. Em 1997/1998, além dos efeitos dos elementos climáticos, o aumento da esterilidade de espiguetas pode, também, ter sido associado à maior severidade de mancha-parda, causada pelo fungo Drechslera oryzae, que cresceu linearmente com o período de reinício da irrigação.

Menores índices de colheita, quando o reinício da irrigação ocorreu com os maiores períodos de dias após a colheita, indicam que as plantas da soca investiram menos na produção de grãos que na de palha (Tabela 1). A produtividade da soca de arroz

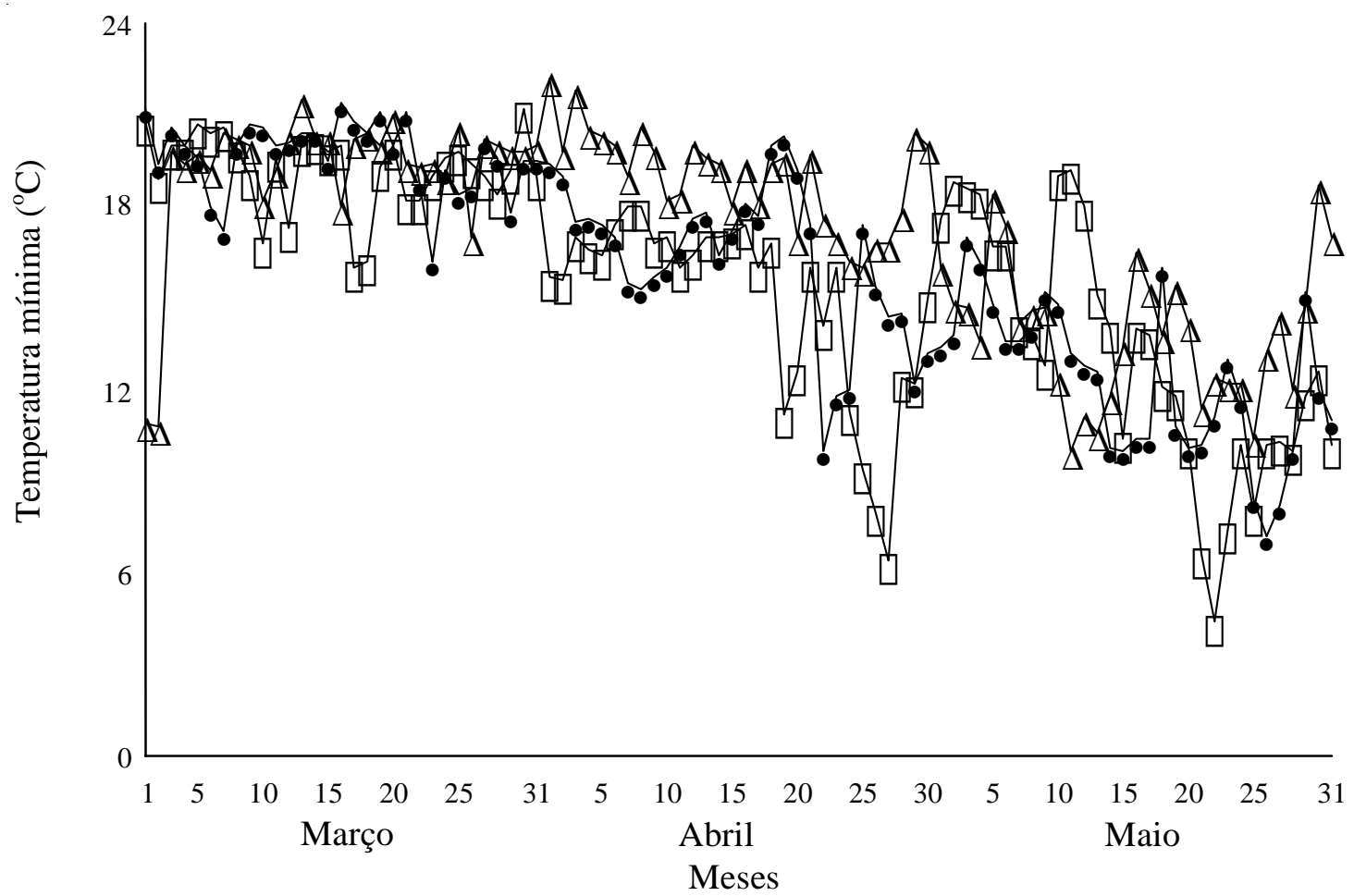

Figura 1. Temperaturas mínimas ocorridas durante o desenvolvimento da soca de arroz irrigado, em $1998(\bullet)$, $1999(\square)$ e $2000(\Delta)$. 
se correlaciona com a sua produção de matéria seca total da parte aérea (Costa et al., 2000b).

Independentemente das condições climáticas do primeiro e do último ano, a massa de 100 grãos declinou com o aumento do período para o reinício da irrigação, e apresentou comportamento semelhante entre os anos (Tabela 1). O déficit hídrico no final da fase vegetativa e na reprodutiva do arroz resulta em decréscimo da massa de grãos (De Datta, 1981). Apenas em 1999/2000, o número de grãos por panícula foi afetado pelo manejo de água, apresentando resposta quadrática, sendo o valor máximo estimado em 38 grãos por panícula, com reinício da irrigação aos 12 dias. Comparando os componentes da produtividade da cultura principal e da soca, Santos et al. (1998) verificaram que o número de grãos por panícula foi o que apresentou as maiores diferenças entre as duas colheitas, pois houve redução em torno de $50 \%$. Os autores concluíram que, para aumentar a produtividade da soca, há necessidade de aumentar este componente, seja por meio do melhoramento das plantas ou do emprego de técnicas de manejo da cultura.

O rendimento industrial dos grãos é um dos parâmetros importantes para determinar o valor de comercialização. Os rendimentos de grãos inteiros e totais da soca foram afetados pelos manejos de água nos dois primeiros anos, apresentando redução no porcentual com o aumento do período para o reinício da irrigação (Tabela 1). Possivelmente, estas características dos grãos não sofreram influência dos tratamentos em 1999/2000 pelo fato de o enchimento e maturação das espiguetas terem ocorrido em condições de temperatura mais favorável. O menor rendimento industrial de grãos nos maiores períodos para o reinício da irrigação pode estar associado à maior severidade de mancha-parda nas folhas. Costa et al. (2000a) verificaram que o valor comercial dos grãos da cultura principal e da soca é semelhante. A classificação visual dos grãos não foi afetada pelo manejo de água.

Tabela 1. Relações significativas entre o reinício da irrigação em diferentes períodos após a colheita da cultura principal e diversas características da soca de arroz irrigado, nos três anos do estudo.

\begin{tabular}{|c|c|c|c|}
\hline Ano & Característica & Equação de regressão & $\begin{array}{c}\text { Coeficiente de } \\
\text { determinação }\left(\mathrm{R}^{2}\right)\end{array}$ \\
\hline $1997 / 1998$ & Panícula $\left(\mathrm{n}^{\mathrm{o}} \mathrm{m}^{-2}\right)$ & $Y=299,8625-2,123 x$ & $0,461 *$ \\
\hline 1998/1999 & Panícula $\left(\mathrm{n}^{\mathrm{o}} \mathrm{m}^{-2}\right)$ & $Y=398,6188-3,407 x$ & $0,999 * *$ \\
\hline $1999 / 2000$ & Panícula $\left(\mathrm{n}^{-} \mathrm{m}^{-2}\right)$ & $Y=754,8563+2,820 x$ & $0,772 * *$ \\
\hline $1997 / 1998$ & Altura de plantas $(\mathrm{cm})$ & $Y=59,0288-0,093 x$ & $0,773 * *$ \\
\hline 1998/1999 & Altura de plantas (cm) & $Y=53,6288-0,168 x$ & $0,949 * *$ \\
\hline $1999 / 2000$ & Altura de plantas (cm) & $Y=58,3750+0,650 x-0,025 x^{2}$ & $0,914 * *$ \\
\hline $1997 / 1998$ & Fertilidade de espiguetas $(\%)$ & $\mathrm{Y}=83,3894-0,311 \mathrm{x}$ & $0,912 * *$ \\
\hline $1999 / 2000$ & Fertilidade de espiguetas (\%) & $Y=89,8113+0,635 x-0,033 x^{2}$ & $0,999 * *$ \\
\hline $1997 / 1998$ & Lesões na folha-bandeira $\left(\mathrm{n}^{\mathrm{o}} \mathrm{cm}^{-2}\right)$ & $\mathrm{Y}=1,2625+0,0299 \mathrm{x}$ & $0,958 * *$ \\
\hline $1997 / 1998$ & Índice de colheita & $Y=0,4681-0,003 x$ & $0,699 * *$ \\
\hline $1998 / 1999$ & Índice de colheita & $Y=0,5671-0,008 x$ & $0,958 * *$ \\
\hline 1998/1999 & Matéria seca total $\left(\mathrm{g} \mathrm{m}^{-2}\right)$ & $Y=626,3172-7,20 x$ & $0,949 * *$ \\
\hline $1997 / 1998$ & Massa de 100 grãos (g) & $Y=2,4748-0,0043 x$ & $0,849 * *$ \\
\hline $1999 / 2000$ & Massa de 100 grãos (g) & $Y=2,4571-0,0045 x$ & $0,899 * *$ \\
\hline $1999 / 2000$ & Grãos por panícula (n⿳0口) & $Y=34,8375+0,5838 x-0,024 x^{2}$ & $0,834 * *$ \\
\hline $1997 / 1998$ & Rendimento de grãos inteiros $(\%)$ & $Y=52,3536-0,222 x$ & $0,733 * *$ \\
\hline 1998/1999 & Rendimento de grãos inteiros $(\%)$ & $Y=45,9813-0,232 x$ & $0,949 * *$ \\
\hline $1997 / 1998$ & Rendimento industrial total de grãos $(\%)$ & $Y=61,5276-0,075 x$ & $0,656^{*}$ \\
\hline $1998 / 1999$ & Rendimento industrial total de grãos (\%) & $Y=60,9944-0,264 x$ & $0,933 * *$ \\
\hline $1997 / 1998$ & Temperatura de gelatinização (notas) & $Y=4,3963+0,011 x$ & $0,766^{*}$ \\
\hline $1998 / 1999$ & Teor de amilose $(\%)$ & $Y=30,6938-0,018 x$ & $0,741 *$ \\
\hline $1997 / 1998$ & Larvas de $O$. oryzae $\left(\mathrm{n}^{-}\right.$amostra $\left.^{-1}\right)$ & $Y=2,8272-0,019 x$ & $0,914 * *$ \\
\hline $1998 / 1999$ & Larvas de $O$. oryzae $\left(\mathrm{n}^{\mathrm{0}} \operatorname{amostra}^{-1}\right)$ & $Y=16,062-0,130 x$ & $0,826^{*}$ \\
\hline
\end{tabular}

* e **Significativo a $5 \%$ e a $1 \%$ de probabilidade, respectivamente. 
A temperatura de gelatinização (TG) do amido refere-se à temperatura de cozimento na qual a água é absorvida e os grânulos de amido aumentam irreversivelmente de tamanho com simultânea perda de cristalinidade (Vieira \& Carvalho, 1999). A TG é expressa por notas de 1 a 3 (alta), de 4 a 5 (intermediária) e de 6 a 7 (baixa). Em 1997/1998, o aumento do período para o reinício da irrigação após a colheita aumentou a TG dos grãos da soca (Tabela 1), mas, esse incremento não foi suficiente para alterar a classificação dos grãos, no que diz respeito às características físico-químicas do produto. Assim, os grãos foram classificados com TG intermediária, o que atende as preferências de consumo no Brasil, pois apresenta um comportamento culinário do arroz. $\mathrm{O}$ teor de amilose foi influenciado pelo manejo de água somente em 1998/1999, porém, os valores situaram-se entre intermediários e altos, compreendendo os grãos que, quando cozidos, apresentam-se secos e soltos, atendendo, também, as preferências do consumidor brasileiro.

Nos dois primeiros anos, as produtividades declinaram linearmente com o aumento do período para o reinício da irrigação (Figura 2); isto foi causado, provavelmente, pela redução de seus componentes. As maiores produtividades de grãos obtidas com o reinício da irrigação imediatamente após o corte da cultura principal estão de acordo com os resultados de Mengel \& Wilson (1981), e contrariam os de Coale

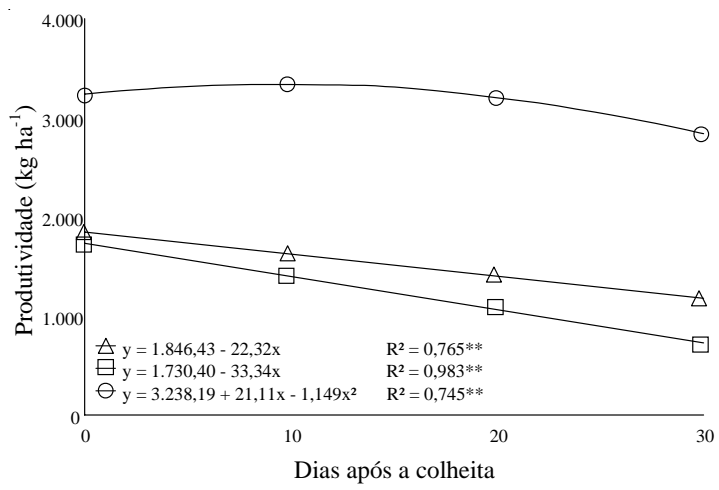

Figura 2. Influência do reinício da irrigação em diferentes períodos após a colheita da cultura principal sobre a produtividade da soca de arroz irrigado em 1997/1998(•), 1998/1999 $(\Delta)$ e $1999 / 2000(\square)$. ${ }^{* *}$ Significativo a $1 \%$ de probabilidade.
\& Jones (1994). No último ano, a resposta foi quadrática, e a produtividade máxima estimada, de $3.335 \mathrm{~kg} \mathrm{ha}^{-1}$, com o reinício da irrigação nove dias após o corte das plantas. Esta produtividade foi refletida pelo maior número de panículas por área, fertilidade de espiguetas, e, conseqüentemente, maior número de grãos por panícula, neste período. A ocorrência de temperaturas mais favoráveis ao desenvolvimento da soca, neste ano, resultou na obtenção de produtividades mais elevadas que nos demais anos. Este resultado é importante na lavoura, pois possibilita a brotação das plantas danificadas pelo pisoteio das esteiras das colhedoras antes do reinício da irrigação. Quando a inundação não ocorre antes do início da fase reprodutiva do arroz, a produtividade é reduzida (De Datta, 1981; Yoshida, 1981). Coale \& Jones (1994) verificaram que os períodos de drenagem a partir da maturação da cultura principal causaram resposta quadrática da produtividade da soca, e a produtividade máxima foi estimada com 28 dias. Os autores sugeriram que esta resposta resultou dos efeitos combinados do aumento do estresse hídrico e da disponibilidade de $\mathrm{N}$ mineral, resultante da oxidação da matéria orgânica, com o aumento do período de drenagem, expressando alterações no número e na massa de grãos.

A infestação de larvas de Oryzophagus oryzae no início dos tratamentos foi pequena em 1998/1999, e média em 1998/1999 e 1999/2000. Em geral, houve redução do número de larvas com os períodos de drenagem (Tabela 2). Mediante amostragens realizadas antes do estabelecimento das drenagens nas diferentes datas, observaram-se decréscimos do número de larvas com a manutenção da lâmina de água além de 80 dias, que são representados por relações lineares significativas, explicando $91,4 \%$ e $82,6 \%$ da variação do número de larvas no primeiro e segundo anos, respectivamente (Tabela 1). Isto sugere ser um fenômeno natural relacionado com a biologia do inseto (Ferreira, 1999), que ocorre, provavelmente, com as larvas de sua segunda geração em plantios feitos em meados de outubro, as quais favorecem a sobrevivência da espécie na entressafra. Se existiu algum efeito do manejo de água sobre as populações de larvas, ele ficou confundido com a flutuação natural do inseto. Entretanto, isto não exclui a possibilidade de o inseto ter causado dano ao arroz, principalmente nos dois últimos anos, onde há evidências de ter 
sido alta a sua ocorrência na fase inicial de desenvolvimento da cultura. As amostragens e as aplicações dos tratamentos foram realizadas após o florescimento do arroz, e, possivelmente, depois de haver causado o principal dano. No último ano, as produtividades da cultura principal e da soca correlacionaram-se negativamente com o número de larvas de $O$. oryzae em duas avaliações, embora nãosignificativas $(\mathrm{P}<0,05)$. Isto indica que a soca, apesar de ser uma das garantias de sobrevivência da espécie na entressafra, aparentemente não se apresenta favorável ao desenvolvimento de populações daninhas do inseto. Portanto, a necessidade de se fazer um controle de $O$. oryzae durante a exploração da soca mostra-se bastante remota.

O consumo de água verificado durante o período de irrigação da soca $(64,54,44$ e 34 dias) nos quatro períodos para o reinício da irrigação $(0,10,20$ e 30 dias após a colheita da cultura principal) pode ser observado na Tabela 3. A área experimental apresentou elevadas perdas por percolação e fluxo lateral; assim qualquer redução no período de irrigação acarretaria considerável economia de água. $\mathrm{O}$ tratamento que propiciou maior produtividade foi a irrigação iniciada aos nove dias após a colheita, com consumo de água igual a $3.443 \mathrm{~mm}$. Isto significa uma economia de água de cerca de $14 \%$ em relação ao tratamento em que não houve drenagem.

Tabela 2. Influência do período de drenagem antes da colheita e do reinício da irrigação aos $0,10,20$ e 30 dias após a colheita (DAC) na infestação de larvas de Oryzophagus oryzae na cultura principal e na soca de arroz irrigado.

\begin{tabular}{|c|c|c|c|c|c|c|c|}
\hline \multirow{3}{*}{$\begin{array}{l}\text { Período de } \\
\text { drenagem } \\
\text { (dia) }\end{array}$} & \multirow{3}{*}{$\begin{array}{l}\text { Reinício da } \\
\text { irrigação } \\
\text { (DAC) }\end{array}$} & \multicolumn{6}{|c|}{ Número médio de larvas por amostra } \\
\hline & & \multicolumn{2}{|c|}{$1997 / 1998^{(1)}$} & \multicolumn{2}{|c|}{$1998 / 1999^{(1)}$} & \multicolumn{2}{|c|}{$1999 / 2000^{(2)}$} \\
\hline & & Inicial & Final & Inicial & Final & Inicial & Final \\
\hline 30 & 0 & 1,1 & 1,0 & 4,8 & 1,5 & 3,8 & 1,1 \\
\hline 30 & 10 & 0,8 & 0,0 & 8,1 & 0,8 & 2,3 & 0,0 \\
\hline 30 & 20 & 1,1 & 0,4 & 5,9 & - & 2,9 & 0,1 \\
\hline 30 & 30 & 1,4 & 0,0 & 5,3 & - & 3,1 & 1,4 \\
\hline 20 & 0 & 1,6 & 1,8 & 1,9 & 0,3 & 2,9 & 0,1 \\
\hline 20 & 10 & 0,6 & 0,5 & 2,8 & 0,3 & 2,6 & 0,8 \\
\hline 20 & 20 & 1,6 & 0,1 & 3,1 & - & 7,0 & 0,5 \\
\hline 20 & 30 & 1,0 & 0,0 & 2,3 & - & 5,3 & 0,5 \\
\hline 10 & 0 & 0,8 & 0,1 & 0,9 & - & 4,6 & 1,6 \\
\hline 10 & 10 & 0,5 & 0,3 & 0,3 & 0,3 & 3,9 & 1,4 \\
\hline 10 & 20 & 1,9 & 0,3 & 1,0 & - & 1,8 & 1,0 \\
\hline 10 & 30 & 0,9 & 0,1 & 1,6 & - & 2,9 & 0,9 \\
\hline 0 & 0 & 1,1 & 1,1 & 1,5 & - & 3,9 & 0,6 \\
\hline 0 & 10 & 1,0 & 0,3 & 0,5 & 0,1 & 3,0 & 0,5 \\
\hline 0 & 20 & 0,4 & 0,3 & 0,8 & - & 2,1 & 1,1 \\
\hline 0 & 30 & 0,9 & 0,1 & 1,1 & - & 2,5 & 0,9 \\
\hline Média & & 1,0 & 0,4 & 3,1 & 0,6 & 3,4 & 0,8 \\
\hline
\end{tabular}

(1)As avaliações foram realizadas no início e no final dos tratamentos indicados. ${ }^{(2)}$ As avaliações foram realizadas aos 30 dias antes e 30 dias após a colheita da cultura principal.
Tabela 3. Percolação e fluxo lateral, evapotranspiração e consumo de água durante o período de irrigação da soca de arroz, que corresponderam ao reinício da irrigação aos 0 , 10, 20 e 30 dias após a colheita (DAC) da cultura principal.

\begin{tabular}{ccccc}
\hline $\begin{array}{c}\text { Reinício da } \\
\text { irrigação } \\
\text { (DAC) }\end{array}$ & $\begin{array}{c}\text { Duração da } \\
\text { irrigação } \\
\text { (dia) }\end{array}$ & $\begin{array}{c}\text { Percolação } \\
\text { e fluxo } \\
\text { lateral }(\mathrm{mm})\end{array}$ & $\begin{array}{c}\text { Evapotrans- } \\
\text { piração } \\
(\mathrm{mm})\end{array}$ & $\begin{array}{c}\text { Consumo } \\
\text { de água } \\
(\mathrm{mm})\end{array}$ \\
\hline 0 & 64 & $3.731,2$ & 279,8 & $4.011,0$ \\
10 & 54 & $3.148,2$ & 235,9 & $3.384,1$ \\
20 & 44 & $2.565,2$ & 195,3 & $2.760,5$ \\
30 & 34 & $1.982,2$ & 148,4 & $2.130,6$ \\
\hline
\end{tabular}

\section{Conclusões}

1. A irrigação reiniciada nove dias após a colheita da cultura principal propicia melhor comportamento da soca de arroz e menor requerimento de água, em relação à inundação imediatamente após a colheita.

2. O valor de comercialização e as características físico-químicas dos grãos da soca somente são afetados pelo manejo da irrigação em condições de temperatura menos favorável ao seu desenvolvimento.

3. A soca aparentemente não favorece o desenvolvimento de populações daninhas de Oryzophagus oryzae.

4. O manejo de água antes da colheita da cultura principal não afeta o desempenho da soca de arroz irrigado.

\section{Referências}

BAHAR, F. A.; DE DATTA, S. K. Prospects of increasing tropical rice production through ratooning. Agronomy Journal, Madison, v. 69, n. 4, p. 536-540, 1977.

CHAUHAN, J. S.; VERGARA, B. S.; LOPES, F. S. S. Rice ratooning. IRRI Research Paper Series, Manila, n. 102, p. 1-19, 1985.

COALE, F. J.; JONES, D. B. Reflood timing for ratoon rice grown on everglades histosols. Agronomy Journal, Madison, v. 86, n. 3, p. 478-482, 1994.

COstA, E. G. de C.; SANTOS, A. B. dos; ZIMMERMANN, F. J. P. Características agronômicas da cultura principal e da soca de arroz irrigado. Ciência e Agrotecnologia, Lavras, v. 24, n. 4, p. 15-24, 2000a.

COSTA, E. G. de C.; SANTOS, A. B. dos; ZIMMERMANN, F. J. P. Crescimento da cultura principal e da soca de genótipos de arroz irrigado por inundação. Pesquisa Agropecuária Brasileira, Brasília, v. 35, n. 10, p. 1949-1958, out. 2000b. 
DE DATTA, S. K. Principles and practices of rice production. New York: J. Wiley, 1981. 618 p.

DE DATTA, S. K.; BERNASOR, P. C. Agronomic principles and practices of rice ratooning. In: INTERNATIONAL RICE RESEARCH INSTITUTE (Los Baños, Filipinas). Rice ratooning. Manila, 1988. p. 163-176.

DOORENBOS, J.; PRUITT, W. O. Las necesidades de agua de los cultivos. Roma: FAO, 1976. (Estudio FAO Riego y Drenaje, 24).

FERREIRA, E. Pragas e seu controle. In: VIEIRA, N. R. de A.; SANTOS, A. B. dos; SANT'ANA, E. P. (Ed.). A cultura do arroz no Brasil. Santo Antônio de Goiás: Embrapa-CNPAF, 1999. p. 197-261.

JENNINGS, P. R.; COFFMAN, W. R.; KAUFFMAN, H. E. Rice improvement. Los Baños: International Rice Research Institute, 1979. 186 p.

MENGEL, D. B.; WILSON, F. E. Water management and nitrogen fertilization of ratoon crop rice. Agronomy Journal, Madison, v. 73, n. 6, p. 1008-1010, 1981.

NADAL, A. M.; CARANGAL, V. R. Performance of the main and ratoon crops of thirteen advanced rice selections under dry-seeded rainfed bunted conditions. Philippines Journal of Crop Science, Manila, v. 4, n. 2/3, p. 95-101, 1979.

PRASHAR, C. R. K. Paddy ratoons. World Crops, London, v. 22, n. 3, p. 145-147, 1970a.
PRASHAR, C. R. K. Some factors governing rice ratoon yield. Plant and Soil, The Hague, v. 32, p. 540-541, $1970 b$.

SANTOS, A. B. dos. Aproveitamento da soca. In: VIEIRA, N. R. de A.; SANTOS, A. B. dos; SANT'ANA, E. P. (Ed.). A cultura do arroz no Brasil. Santo Antônio de Goiás: Embrapa-CNPAF, 1999. p. 463-492.

SANTOS, A. B. dos; SANTOS, C.; RAMOS, C. G. Avaliação de genótipos de arroz irrigado para o aproveitamento da soca. In: REUNIÃO NACIONAL DE PESQUISA DE ARROZ, 6., 1998, Goiânia. Perspectivas para a cultura do arroz nos ecossistemas de várzeas e terras altas. Goiânia: Embrapa-CNPAF, 1998. p. 147-149. (Documentos, 85).

STONE, L. F.; MOREIRA, J. A. A.; SILVEIRA FILHO, A. Manejo de água na cultura do arroz: consumo, ocorrência de plantas daninhas, absorção de nutrientes e características produtivas. Pesquisa Agropecuária Brasileira, Brasília, v. 25, n. 3, p. 323-337, mar. 1990.

VIEIRA, N. R. de A.; CARVALHO, J. L. V. de. Qualidade tecnológica. In: VIEIRA, N. R. de A.; SANTOS, A. B. dos; SANT'ANA, E. P. (Ed.). A cultura do arroz no Brasil. Santo Antônio de Goiás: Embrapa-CNPAF, 1999. p. 582-604.

VOTONG, V. The effect of time of drainage and time of rewatering on the yield of ratoon rice. 1975. $106 \mathrm{p}$. Dissertation (M.Sc.) - University of Sydney, Sydney.

YOSHIDA, S. Fundamentals of rice crop science. Los Baños: International Rice Research Institute, 1981. 269 p. 